\title{
Interfacial rheology: An overview of measuring techniques and its role in dispersions and electrospinning
}

\author{
JAN PELIPENKO \\ JULIJANA KRISTL* \\ ROMANA ROŠIC \\ SAŠA BAUMGARTNER \\ PETRA KOCBEK \\ University of Ljubljana, Faculty \\ of Pharmacy, Ljubljana, Slovenia
}

Accepted May 1, 2012

\begin{abstract}
Interfacial rheological properties have yet to be thoroughly explored. Only recently, methods have been introduced that provide sufficient sensitivity to reliably determine viscoelastic interfacial properties. In general, interfacial rheology describes the relationship between the deformation of an interface and the stresses exerted on it. Due to the variety in deformations of the interfacial layer (shear and expansions or compressions), the field of interfacial rheology is divided into the subcategories of shear and dilatational rheology. While shear rheology is primarily linked to the long-term stability of dispersions, dilatational rheology provides information regarding short-term stability. Interfacial rheological characteristics become relevant in systems with large interfacial areas, such as emulsions and foams, and in processes that lead to a large increase in the interfacial area, such as electrospinning of nanofibers.
\end{abstract}

Keywords: interfacial rheology, emulsions, foams, electrospinning, nanofibers, nanotechnology

Colloidal disperse systems represent the increasing number of modern delivery systems whose primary characteristic, a large interfacial area, causes thermodynamic instability. Therefore, the foremost challenge in dispersion design is the reduction of interface instability and an understanding of the behaviour of interfaces. Interfacial rheology is one of the most powerful tools for observing occurrences at the interphase. As previously mentioned, the stability of such systems is provided by the formation of a stable interfacial layer of surfactants around each dispersible particle. The stability of these systems can be improved by using more than one surfactant, but it must be kept in mind that different surfactants can have varying mechanisms of stabilisation, some of which can be mutually incompatible. Surfactant selection is therefore crucial and must be based on physicochemical properties, stability of the interfacial film, mobility of the molecules in the interfacial film, HLB, film formation kinetics, compatibility and interactions between molecules on the surface, CMC, etc. (1). Interfacial characteristics do not

* Correspondence; e-mail: julijana.kristl@ffa.uni-lj.si 
only affect the stability of foams and emulsions but also influence a variety of technological processes, such as electrospinning (2), mass transfer, foaming, emulsification, oil-recovery and high-speed coating (3). Numerous reports dealing with the effects of incorporated surfactants on dispersion stability in correlation with rheological parameters can be found in the literature (4-6). However, most of the previously studied systems were largely analysed from the perspective of rheology, which is better understood than interfacial rheology. Rheology is a characteristic of a system and is independent of the plane in which it is measured; hence, it can be also called three-dimensional rheology. In contrast, interfacial rheology is restricted to the interfacial layer and therefore can be called two-dimensional rheology. As interfacial rheology explores rheological properties directly at the interphase, which is a key to dispersion stability, we believe that it is much better correlated to the stability of dispersions than rheology. However, the effects of interfacial rheological characteristics on dispersion stability and the electrospinning process have not been widely discussed or systematically investigated thus far.

Interfacial characteristics are generally dependent on the behaviour of both phases. Moreover, these characteristics exhibit even greater dependency on the behaviour of the molecules positioned at the interface, particularly on their chemical composition, concentration and interactions. These molecules are amphiphilic, meaning that they have an affinity for the hydrophilic and lipophilic phase and can be called surfactants. A wide variety of low- and high-molecular-weight surfactants are frequently used in pharmaceuticals, cosmetics and food products among their other applications. Complex interfacial structures are present not only in these products but also in biological systems such as cell membranes $(7,8)$ and the surfactant film on lung alveoli $(9,10)$. Furthermore, the majority of natural biochemical reactions occur at interfaces, and only by understanding interfacial characteristics, we are able to explain these processes and successfully mimic biological systems. Given these facts, familiarity with the methods that allow determination of interfacial characteristics, and thus predict system behaviours, is critical. Interfacial rheological measurements are challenging, not only because of the extremely low forces that are needed to influence the interface, but primarily because of the flow of the interface, which can cause deformation of the surrounding bulk phase. Thus, the main objective of these measuring techniques is to examine the interface with sufficient sensitivity and to minimise any alteration of the interfacial structure (11) while preventing any change in the behaviour of deeper layers.

The aim of this paper is to highlight the impact of interfacial rheological characteristics on the properties of various systems. Theory of interfacial rheology, an overview of available measuring techniques, the role of interfacial rheology at liquid-liquid or gas-liquid interfaces and the electrospinning process are presented.

\section{INTERFACIAL RHEOLOGY: THEORY AND AVAILABLE MEASURING TECHNIQUES}

Rheology was defined by Bingham in 1929 as the science of deformation and flow under controlled testing conditions. The term »rheology« originates from the Greek word »rheos « meaning »flowing « or »streaming «, thus rheology is actually »flow science«, which is based on the fundamental physical relationships concerning how materials respond to applied forces or deformations (12). 
Interfaces were first mentioned in the $19^{\text {th }}$ century, when the Paris Academy of Sciences published a paper on the behaviour of the layer that occurs at the interface between an oil and an aqueous protein solution. The first experiment at an interface was performed 25 years later by Plateau, who compared the dumping of an oscillating magnetic needle on bare and surfactant-laden interfaces (3). He discovered that the needle was better immersed when a surfactant was present, but he could not explain why. This phenomenon was later described by Marangoni, who explained that this result is due to surface compression at the front of the needle and dilation on the opposite side, causing a surface tension gradient that influences the movement of the needle. At the beginning of the $20^{\text {th }}$ century, Joseph Valentin Boussinesq proposed a theoretical model for the deformation of two-dimensional liquids, which was later improved by other scientists (13). These early studies were the basis for developing various models and measuring techniques in rheology as well as in interfacial rheology.

\section{Basic equations and models in rheology and interfacial rheology}

Interfacial rheology studies the response of mobile interfaces to shear (changes in shape at constant area) and/or dilatational deformation (changes in surface area with constant shape). Thus, we distinguish shear and dilatational interfacial rheological parameters. Interfacial shear viscosity $\left(\eta_{\mathrm{s}}\right)$ is the ratio between the shear stress $(\sigma)$ and the shear rate $(\dot{Y})$ in the plane of the interface $\left(\eta_{\mathrm{s}}=\sigma / \dot{Y}\right)$ and can be called two-dimensional viscosity (14), while the interfacial dilatational viscosity $\left(\eta_{\mathrm{d}}\right)$ can be defined as the uniform expansion of the interface at a constant rate $\left(\eta_{\mathrm{d}}=d_{Y} / d \ln A d t\right)$.

According to Boussinesq, interfacial rheology (flow in two dimensions) can be considered analogous to rheology (flow in three dimensions), and like in three-dimensional rheology, springs and dashpots can be used to simulate rheological behaviour of the tested systems. Springs are used to simulate ideal elastic behaviour and can be described by Hook's law (Fig. 1A), while a dashpot is used to simulate plastic behaviour of the interface (Fig. 1B).

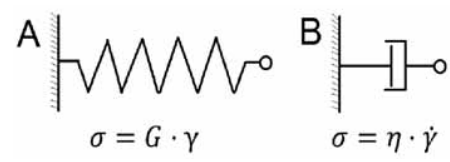

Fig. 1. Schemes of (A) spring, simulating elastic behaviour, and (B) dashpot, simulating plastic behaviour with their corresponding equations, where $\sigma$ represents stress, $G$ is spring constant and $\gamma$ is deformation, while $\eta$ represents viscosity and $(Y)$ shear rate $(15,16)$.

Steady state is defined as a state in which the molecules at the interface are in their thermodynamically most favoured state. When this interface is deformed, thermodynamic forces tend to restore the original state; however, under ordinary circumstances, restoration of the interfacial film is only partial, meaning that the interface simultaneously exhibits plastic and elastic characteristics. Consequently, various mathematical models were proposed to approximate the viscoelastic behaviour of the samples by combining spring and dashpot models. Among these mathematical representations, the best known 


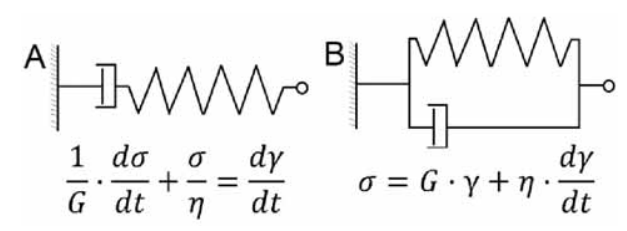

Fig. 2. Schemes of (A) Maxwellian model, and (B) Kelvin-Voigt model with the corresponding equations (15).

is the Maxwellian model (Fig. 2A). Viscoelastic liquids that obey the Maxwellian model include pitch, bees wax, ice-cream and concentrated solutions of polymers $(15,16)$; however, the primary disadvantage of this model is its inadequacy for predicting creep and recovery. In contrast, the Kelvin-Voight model (Fig. 2B) is acceptable as a first approximation for creep and recovery behaviour, but it is insufficient for predicting relaxation and, therefore, can be used only for elastic systems with weak viscosity characteristics $(15,16)$. To improve the prediction of creep and recovery or to improve the prediction of relaxation, more complex models have been proposed (Linear and Burger models) $(15,17)$.

Viscoelastic characteristics of the bulk or interfaces can be determined using stress relaxation, strain relaxation and/or oscillatory measurements. In a stress relaxation test, a sudden strain is applied at the interface and the stress $(\sigma)$ is measured as a function of time, while in the strain relaxation experiments, a small constant stress is applied to the interfacial film.

In oscillatory experiments, the strain or stress is varied periodically with a sinusoidal alteration at a chosen angular frequency $(w)$. The complex modulus $\left(G^{*}\right)$ is obtained from the amplitude ratio of stress or strain. $G^{*}$ consists of the elastic $\left(G^{\prime}\right)$ modulus and the plastic $\left(G^{\prime \prime}\right)$ modulus, where $G^{\prime}$ is the real part of the complex modulus and represents the energy stored during stress, while $G^{\prime \prime}$ is the imaginary part of the complex modulus and represents the energy that is lost during sample loading (14).

\section{Shear measuring techniques}

In the past few decades, numerous measuring techniques have been proposed for determination of the interfacial rheological parameters of fluids and semisolid dispersions, all of which have advantages and limitations with respect to the operating range, sensitivity and suitability for measuring different interfaces (18). Shear interfacial rheological methods involve inducing shear in the adsorbed film without changing the area. These methods provide information on the structures formed at the interface $(3,8,19)$. These techniques are most commonly used for the adsorption layers of protein or combinations of protein and low-molecular-weight surfactants and can be divided into direct and indirect methods.

Indirect techniques measure surface velocity profiles using inert visible particles, on the basis of which shear interfacial characteristics can be determined. These methods are primarily limited to gas-liquid interfaces. The most commonly used indirect viscometer is the deep-channel surface viscometer, which consists of two stationary concentric cylinders and a rotating dish filled with the test sample (Fig. 3A). The chamber is rotated at a known 

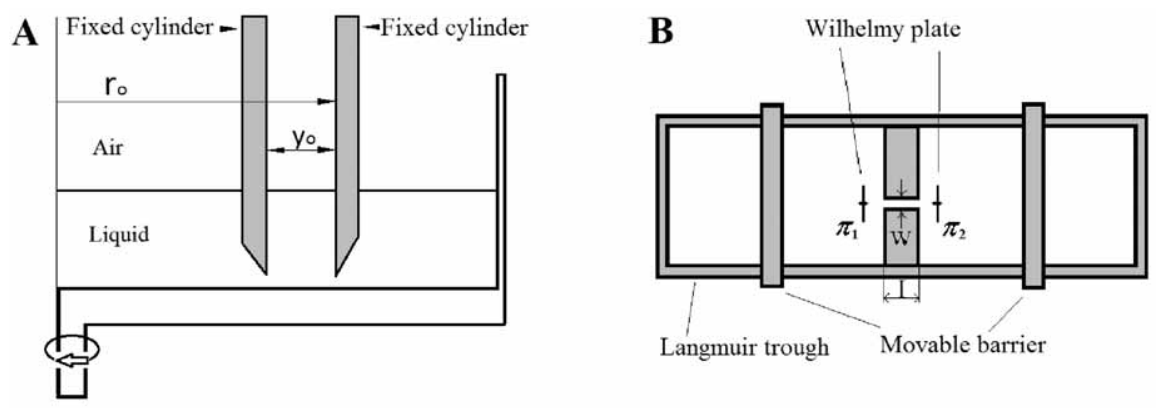

Fig. 3. (A) Scheme of a deep-channel surface viscometer, (B) scheme of a channel surface viscometer.

angular velocity $\left(\omega_{0}\right)$ and surface motion between the cylinders is measured using talc or Teflon particles placed within the fluid interface. The primary advantage of the deep-channel viscometer is that it can be also used for exploring liquid-liquid interfaces. Another common indirect viscometer is the channel surface viscometer (Fig. 3B), where $\eta_{\mathrm{s}}$ is determined by the measurement of the flow rate of a film through a narrow channel under an applied pressure differential, $\Delta \pi(15,20)$. Unfortunately, the channel surface viscometer is limited to studies of insoluble monolayers at gas-liquid interfaces.

Direct methods, in contrast to indirect ones, determine the shear stress of the liquid interface as it is stressed by contact with a foreign body. Most of the commonly used rheometers in this field are torsion pendulum surface viscometers, which can be further divided into those with sharp-edge geometry suitable for gas-liquid interfaces and those with biconal disk geometry, which can be also used at liquid-liquid interfaces. Although various touching bodies can be used (Fig. 4), the principles for determining rheological parameters are similar in most cases: a rotating or oscillating touching body is connected to a motor that can detect torque and displacement while the sample is held in a stationary tempered dish $(13,15,20)$.

In addition, a magnetic rod viscometer can be included among the interfacial shear rheometers (Fig. 5). This viscometer is one of the most sensitive instruments for measuring interfacial shear rheological parameters (21) and is capable of measuring surface shear

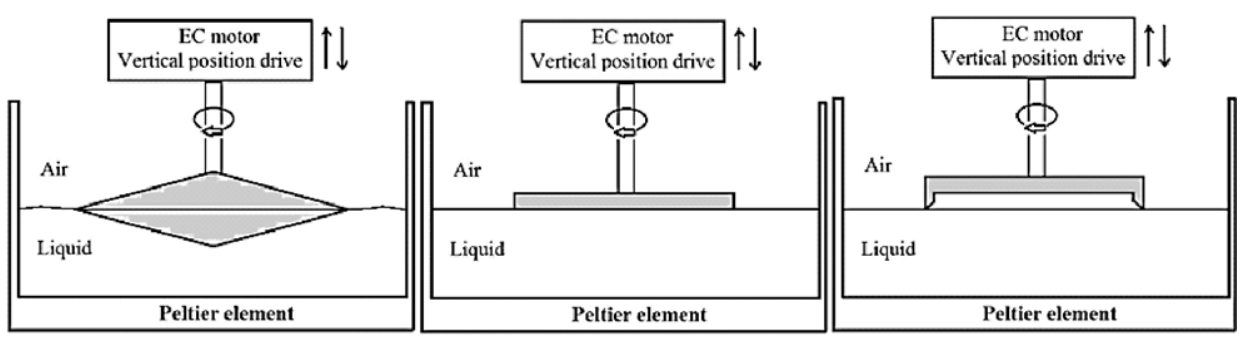

Fig. 4. Schemes of different interfacial measuring systems. From left to right: bicone system, plate-plate system and knife-edge torsion pendulum technique. 


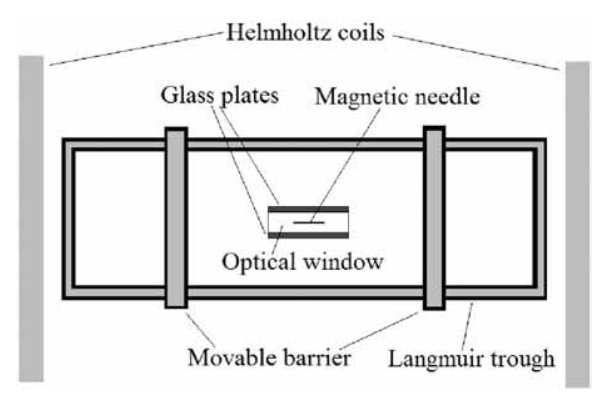

Fig. 5. Schematic presentation of a magnetic rod surface viscometer.

moduli in a wide range of values (22). The prime feature of this rheometer is its long magnetic needle floating at the interface, which is moved by an external magnetic field $(15,22,23)$. Its primary advantage over torsion pendulum surface viscometers is that it can be combined with a Langmuir trough, which enables control of the thermodynamic state of the interfacial monolayer (13).

\section{Dilatational measuring techniques}

Dilatational measuring techniques induce a change in the interfacial area while simultaneously measuring the interfacial tension to provide information regarding the composition of interfacial layers. Thus, with interfacial dilatational rheology, we can observe the rheological properties that arise in response to changes in the surface area. These changes are strongly evident in the foamability, emulsion formation and electrospinning during which an enormous increase in surface area occurs.

Dilatational measuring techniques are used to investigate the equilibrium and dynamic properties of simple and complex interfacial layers composed of low-molecular-weight surfactants (LMWS), proteins and polymers (24). Furthermore, these techniques can be used to monitor surfactant concentration, competitive adsorption and the magnitude of interactions at the interface. Measurements are based on parameters that strongly correlate with the equilibrium properties of the adsorption layers and the mechanisms that control their formation.

Within the discipline of dilatational rheology, various techniques have been developed for use in different fields. A capillary wave damping instrument is used to investigate the dynamic properties and structures of insoluble monolayers or adsorption layers $(25,26)$. In the last twenty years, oscillating drop and bubble techniques have been developed and are now the most commonly used techniques for surface dilatational rheology (3). These techniques can be used to study rheological properties at both liquid-liquid and gas-liquid interfaces and are based on either the shape measurement of a drop/ bubble or on the measurement of the capillary pressure inside a drop/bubble (24).

The drop/bubble profile tensiometer, presented in Fig. 6, is widely used for the determination of mechanical properties at gas-liquid and liquid-liquid interfaces, and is applicable to a great variety of liquids, from organic to molten metals, for which very small amounts of sample are required. Major drawbacks of the method include the requisite density difference between the two involved fluids and the requirement that the inter- 


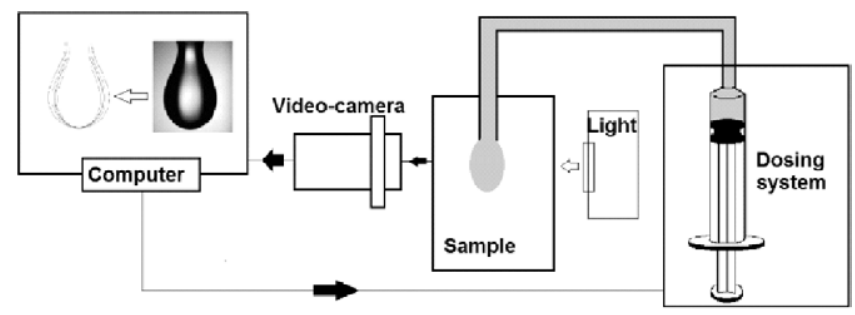

Fig. 6. Scheme of drop/bubble profile tensiometry (DPT). Under the influence of external forces, a drop/bubble of one liquid inside another assumes a shape that minimises the total energy of the system and provides maximum stability.

face must be close to mechanical equilibrium when it is analysed (the interface must be investigated at low frequencies) (24). The drop/bubble shape is defined by a combination of surface tension and gravitational force: surface forces prefer spherical drops/bubbles, and gravity attempts to elongate or compress the drop/bubble. Surface tension and surface curvature at each point on the surface of a drop/bubble are provided by the Laplace equation $(13,27)$.

The principle of capillary pressure tensiometry (CPT) is shown in Fig. 7. CPT is a versatile technique utilised by a variety of methods for investigating dynamic and equilibrium systems at liquid-liquid and gas-liquid interfaces. This technique is also the only dilatational rheological method that can be used for two liquids with a small density difference $(28,29)$. The principle is based on direct measurement of the pressure difference between two phases separated by the spherical interface of a drop/bubble (15). The device required for this measurement is typically composed of two chambers connected by a capillary tube. While one of the chambers is closed and includes a pressure sensor and piezoelectric element, the other is used as a reference for the volume of a drop/bubble, which is formed at the tip of the capillary. The diameter of a droplet is determined by either taking its picture or calculating it on the basis of the volume of injected fluid $(3,24,30)$.

Both shear and dilatational interfacial rheology offer diverse techniques for the determination of rheological properties, which differ in sensitivity, range of measurement and applicability to different systems.

Fig. 7. Scheme of a measurement cell in an open capillary pressure tensiometer.

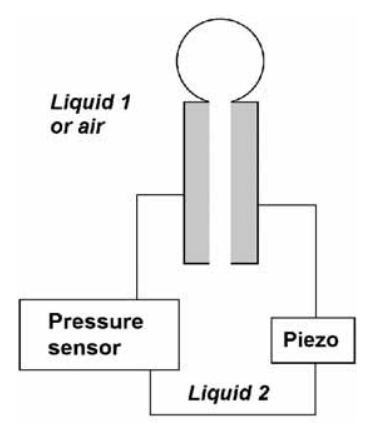


THE ROLE OF INTERFACIAL RHEOLOGY IN DISPERSIONS

Interfacial film is necessary for dispersion stability, but it is also the source of its thermodynamic instability. Therefore, familiarity with the factors influencing interfacial film properties is critical for the determination of these properties.

Interfacial rheology is a sensitive tool used to observe structures that are formed at the interface, define the interactions between the molecules and determine their concentration (31). Dispersion behaviour is known to be affected by the characteristics of interfacial films, and shear rheology is linked to the long-term stability of dispersions, while dilatational rheology provides information regarding short-term stability (32). However, the relationship between interfacial rheological characteristics and dispersion stability is not straightforward (33). Therefore, each system must be treated separately.

\section{Dispersions stabilised with proteins, low-molecular-weight surfactants, or their blends}

Due to their biocompatibility and biodegradability, proteins are commonly used as surfactants in dispersions. When adsorbed at an interface, their conformation is rearranged in such a manner that the hydrophobic parts are exposed to the hydrophobic phase and vice versa. Proteins form an immobile viscoelastic interfacial film with characteristics that depend on the structure of the adsorbed protein and the strength of interactions between protein molecules (31). Interfacial rheological parameters like $G^{\prime}, G^{\prime \prime}$ are generally higher near the iso-electric point, meaning that the $\mathrm{pH}$ also influences the characteristics of the interface (11). Due to the polymeric and polyelectrolytic nature of proteins, the interfacial protein film is assumed to be stabilised by the electrostatic and steric forces between the molecules (8). In contrast, Ventureira and collaborators (34) did not find any correlation between electrostatic forces and the stability of an interfacial film in the case of amaranth protein isolates. Instead, they emphasised the importance of hydrophobic interactions and hydrogen bonding. Although there are conflicting results regarding the mechanism of protein interfacial layer stabilisation, a correlation is believed to exist between the dilatational and shear rheological characteristics of the protein interfacial film, on the one side, and the stability of the colloidal dispersion stabilised by that protein, on the other side. However, due to great diversity in protein characteristics, this correlation must be determined for each system separately.

LMWSs, in contrast to proteins, form a mobile interfacial layer with low viscoelasticity, which is more effective in reducing the dynamic interfacial tension (11). The primary mechanism of stabilisation is the Gibbs-Marangoni effect (31). The interfacial area is greatly increased during emulsifying or foaming, leading to an inhomogeneous distribution of the surfactant at the interface. Variations in surfactant concentration cause diffusion of the surfactant molecules until a uniform film is established. During this process, the liquid can be transported to the interface. This so-called Gibbs-Marangoni effect is the driving force behind stabilisation of a thin fluid film between the droplets, preventing their coalescence (31). Interfacial shear rheological characteristics of dispersions stabilised with LMWSs depend on whether the surfactants are more soluble in the oil or water phase (35). Furthermore, Bykov et al. proved that an increase in the length of the surfactant alkyl chain leads to the formation of a more rigid film structure, which can be 
seen as having higher dilatational elasticity. This effect is better seen at low surfactant concentrations because the adsorption layer is more homogeneous at such concentrations (36).

Each of the above-mentioned surfactant groups, when alone, is effective at stabilising a dispersion. However, in the pharmaceutical, cosmetics and food industries, blends of both surfactants are often used. The results show that due to slow protein adsorption, the final size of a drop in an emulsion stabilised with proteins depends on the time scale at which the droplets are formed. To cover an oil-water interface more rapidly, LMWSs are often added (33). Because LMWSs displace proteins from the interface and adsorb at the interface much faster, they are often added as protein stabilisers to prevent biological inactivation of the proteins exposed at the interface (37).

Addition of LMWSs to dispersions that are stabilised with proteins can lead to a decrease in dispersion stability due to conflicts between the two different stabilisation mechanisms. Small amounts of LMWSs adsorbed at the interfacial layer disrupt the protein viscoelastic layer, which is then no longer able to stabilise the dispersion by the viscoelastic mechanism. At this stage, however, the concentration of LMWSs is not high enough to provide dispersion stabilisation by the Gibbs-Marangoni effect. As the concentration of LMWSs increases, they displace the proteins from the surface and ultimately stabilise the dispersion by their own mechanism $(19,38)$. Molecules of LMWS at the interface squeeze together more tightly than proteins; thus, in most cases, LMWSs replace proteins at the interface, given a sufficient concentration in the bulk phase. According to the orogenic mechanism, protein displacement by LMWS at a gas-liquid interface has three phases, as shown in Fig. 8. At point (A) where $\pi<\pi_{e}^{\text {protein }}\left(\pi\right.$ is the surface pressure, $\pi_{e}^{\text {protein }}$ is the equilibrium surface pressure of protein), LMWS adsorbs onto small defects in the protein film. At point (B) in which $\pi \approx \pi_{e}^{\text {protein }}$, the surfactant domains continue to grow, while the protein film thickens in response to the decrease in area. Thus, the volume of the adsorbed protein remains constant. In the third phase (C) in which $\pi>\pi_{e}^{\text {protein }}$, the protein network breaks down and the LMWS forms a continuous film. This process is driven by low interactions between the LMWSs and the proteins $(39,40)$. However, one must consider that the kinetics of these processes is to each LMWS/protein combination (31). In contrast to the orogenic mechanism, Bykov et al. suggested the formation of heterogeneous adsorption layers in the case of a polyelectrolyte and an LMWS $(41,42)$.

Distribution of proteins and LMWSs at the interface is determined by the competitive adsorption of both types of surfactants and by the nature of the protein-LMWS interactions, both of which have a distinct impact on the rheological properties of the interface (19). Furthermore, the interfacial viscosity and complex modulus values for adsorbed proteins have been often shown to be much higher than those for LMWSs (43). Therefore, the interactions between surfactants, displacement of proteins by LMWSs, structures at the interface, incompatibilities of surfactants, film composition and the mechanism of interfacial film formation can all be analysed using interfacial rheological methods $(19,20,31)$.

\section{Dispersions stabilised with nanoparticles}

In addition to LMWSs and amphiphilic polymers, nanoparticles can be used to stabilise dispersions. Pickering-Ramsden emulsions are emulsions stabilised with nanopar- 


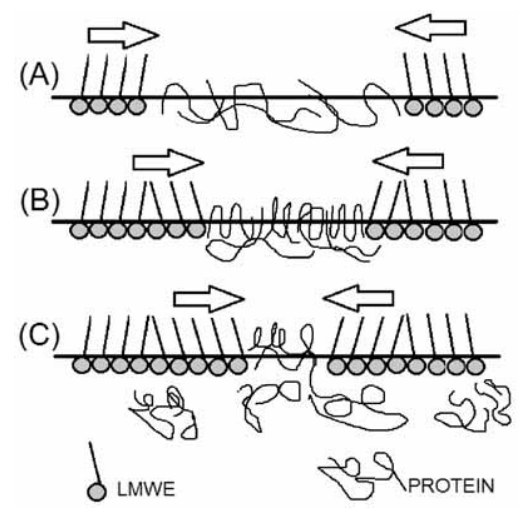

Fig. 8. Protein displacement by LMWS at the liquid-air interface according to the orogenic mechanism.

ticles that are adsorbed at the interface. Their stability depends on the particle concentration, size and shape; an increase in particle concentration suppresses coalescence, and addition of smaller particles leads to a decrease in droplet size (44). Nanoparticles prevent coalescence by forming a robust mechanical monolayer at the interface (11), which can be characterised using interfacial rheological methods. Madivala and co-workers (45) studied the effect of particle shape on emulsion stability in relation to interfacial rheology and found that ellipsoidal particles form a denser structure at the interface, yielding much higher viscoelastic moduli than spherical particles. Furthermore, interfacial rheology can be also used to assess the efficacy of nanoparticle entrapment at the interface of the dispersion in correlation with its stability (44).

\section{Stability of gas-liquid and liquid-liquid interfaces: interfacial rheology as a predictive} tool

Stability of foams and emulsions depends on the stability of the corresponding interfacial layer. There are two main phenomena indicating instability of the interfacial layer: Ostwald ripening and coalescence.

At gas-liquid interfaces (foams), one of the major sources of instability is Ostwald ripening, which shows as slow shrinkage of smaller bubbles, due to gas diffusion from smaller bubbles to larger ones, forced by the Laplace pressure difference between them. According to Henry's law, the solubility of a gas in a liquid is higher around the bubble than in bulk liquid. Consequently, the excess gas diffuses to areas of lower concentration of dissolved gas (e.g., to larger bubbles and to the atmosphere) (46). Another source of instability at liquid-liquid and gas-liquid interfaces is coalescence.

Regardless of the type of dispersion stabiliser, there is a connection between the foaming capacity dynamics and the interfacial rheological characteristics. Formation of a stable gas-liquid interface is based on the diffusion and rapid adsorption of stabilisers on the newly formed surface (47). Optimum foaming capacity is reached with a reduced lag period and with rapid diffusion of the emulsifier toward the interface (19). Croguennec et al. studied the importance of the diffusion rate of the surfactant (48) and compared the stabilisation abilities of native and heat-treated $\beta$-lactoglobulin. Their results 
proved the importance of the kinetic development of a viscoelastic interfacial protein layer on the foam structure and therefore on its stability. The influence of adsorption kinetics was also demonstrated by Maldonado-Valderama et al. (49), who established a link between interfacial viscosity and foamability in addition to highlighting the importance of interfacial film elasticity to foam stability. According to their results, interfacial viscosity is more important to foam formation, while dilatational elasticity has a greater influence on foam stability. Furthermore, Wooster et al. (50) correlated the three-dimensional structure of whey protein with its interfacial rheological characteristics and emphasised the influence of structure on dispersion stability. The effect of protein structure on dispersion stability was also emphasised by Kim and co-workers (51), who found that changes in secondary and ternary structures resulted in increased interfacial shear elasticity and shear viscosity, leading to enhanced dispersion stability.

Physical characteristics of hydrophilic and hydrophobic phases, surfactant characteristics, steric and electrostatic interactions have a great influence on interfacial rheological characteristics and consequently on the formation and properties of a liquid-liquid interface. However, there is no simple connection between emulsion stability and interfacial rheology. Sanfeld and Steinchen concluded that within a given range of parameters, a film's elasticity gives a negligible contribution to its emulsion stability (52). On the other hand, Maldonado-Valderama et al. demonstrated a connection between the interfacial elasticity and coalescence in emulsions stabilised with $\beta$-casein (49). Thus, measurements of interfacial viscosity and other interfacial rheological parameters are useful tools for sensitive detection of structural changes in the interphase that can affect the stability of the observed dispersion systems. However, no simple prediction or general conclusions are possible.

\section{THE ROLE OF INTERFACIAL RHEOLOGICAL CHARACTERISTICS IN THE ELECTROSPINNING PROCESS}

Nanofibers are very tiny, solid fibers with nanometre-scale diameters, theoretically unlimited length, large surface area-to-volume ratio and high porosity. Given their physical characteristics, these materials are used in the chemical, textile, computing, energy, biomedical and pharmaceutical industries (2), in which nanofibers join other, more established drug nanocarriers $(53,54)$. The most commonly used method for nanofiber production is electrospinning-a widely used modern, versatile and one-step method (Fig. 9). Although it was patented more than a hundred years ago by J. F. Cooley, intensive research into the electrospinning process and its utility in the pharmaceutical and tissue engineering fields began in the early 1990's, along with the development of nanotechnology, when research groups demonstrated that many organic polymers could be electrospun into nanofibers (55). We believe that interfacial rheology could be employed also in the formation of nanofibers.

Electrospinning produces nanofibers from polymer solutions using a high-voltage supply. A polymer solution is placed in a plastic syringe with a metallic needle. The syringe is then mounted into a syringe pump to provide a constant flow of polymer solution, and the needle tip is connected to the high-voltage source. At sufficient voltage, the electrostatic repulsion forces prevail over the forces maintaining the spherical shape of 


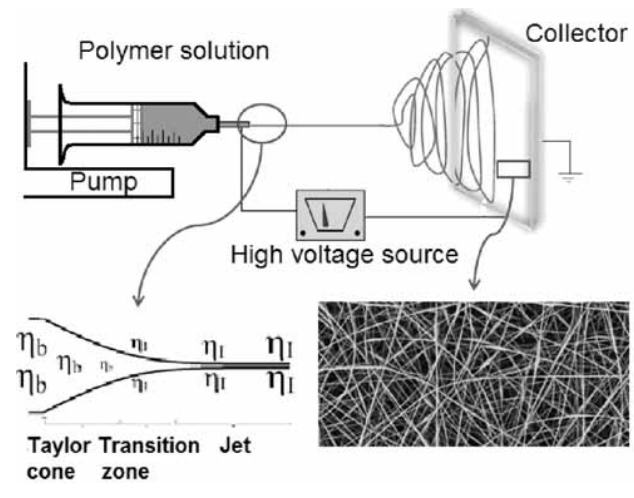

Fig. 9. Scheme of an electrospinning process.

the drop, first forming a Taylor cone, then forming a jet of polymer solution, which seeks a path to the grounded collector (56) (Fig. 9). If the cohesion forces between polymeric molecules are strong enough, the jet that is formed is stable and uniform fibers are obtained (57).

Current state-of-the-art studies of electrospinning process claim that viscosity, surface tension and conductivity of the polymer solution are the primary systemic parameters influencing nanofiber morphology (55-60). However, we believe that interfacial rheological characteristics are decisive in the electrospinning process and should be used as a predictive tool for the success of electrospinning. In our opinion, given the area of a Taylor cone, rheological characteristics still play a significant role due to the larger diameter of the jet. During jet thinning, interfacial characteristics prevail due to the significant increase in the surface-to-volume ratio $\left(S / V=4 D^{-1}\right)$. The jet diameter $(D)$ is reduced from approximately $1 \mathrm{~mm}$ (inner diameter of the needle used) to a few hundred nanometres or less (diameter of the obtained nanofibers). Moreover, solvent evaporation creates a concentration gradient in polymer molecules, leading to a more pronounced effect of the interfacial characteristics. Unfortunately, there is still no interfacial rheological method that would allow simultaneous determination of the interfacial shear properties and the actual dilatational characteristics at expansion rates on the order of $10^{3} \mathrm{~s}^{-1}$ (expansion rates achieved at the beginning of the thin jet region-transition zone). Thus far, the best approximation involves interfacial shear measurements (61).

Not only do the interfacial rheological properties differ from the bulk properties, but they also have a different relationship with polymer concentration. Polymers spontaneously adsorb from aqueous solution at interfaces at which their free energy is lower than it is in solution. During adsorption, polymer molecules alter their conformation; they unfold and establish more intermolecular interactions with other molecules at, or close to, the interface, which leads to the formation of an interfacial film. Interfacial rheological characteristics of the polymer solution depend on various factors, including intrinsic molecular properties and the physicochemical conditions of the solution. Therefore, no precise prediction of interfacial rheological parameters can be achieved on the basis of the rheological parameters determined in the bulk of the polymer solution.

Our research group (2) investigated the correlation between polymer solution composition and nanofiber formation with the emphasis on the predictive power of the most 
commonly described electrospinning systemic parameters and interfacial viscosity (Fig. 10). Solutions of PEO and chitosan $(3 \% w / w)$ were prepared separately, then mixed together in varying mass ratios and finally electrospun using the same process parameters. Surface tension was found to be independent of the polymer solution composition, while the conductivity, viscosity and interfacial viscosity increased as the proportion of chitosan increased. Based on the values of interfacial viscosity, solutions can be divided into three regions coinciding with the morphology of the obtained nanofibers. From solutions processed in the first region, smooth, uniform and bead-free nanofibers were formed. Solutions in the second region formed beaded nanofibers, and only droplets containing a few nanofibers were formed in the solutions in the third region (2).

Based on viscosity, solutions may also be divided into three regions that coincide with the regions of interfacial viscosity; still, the differences among these are much less significant, suggesting higher sensitivity of interfacial rheology for the determination of small differences between the solutions. Therefore, the primary advantage of interfacial shear measurement is higher sensitivity for detecting small changes at the interface. In addition, interfacial shear allows one to investigate the interface without simultaneously influencing the behaviour of deeper layers (62).

Finally, we believe that interfacial rheology could be also employed in the preparation of nanoparticles, owing to the great increase of the interface, and it has been already shown that characteristics of selected surfactants strongly influence nanoparticle formation $(63,64)$.

Fig. 10. Correlation between systemic parameters of polymer solutions and the morphology of obtained nanofibers (2).

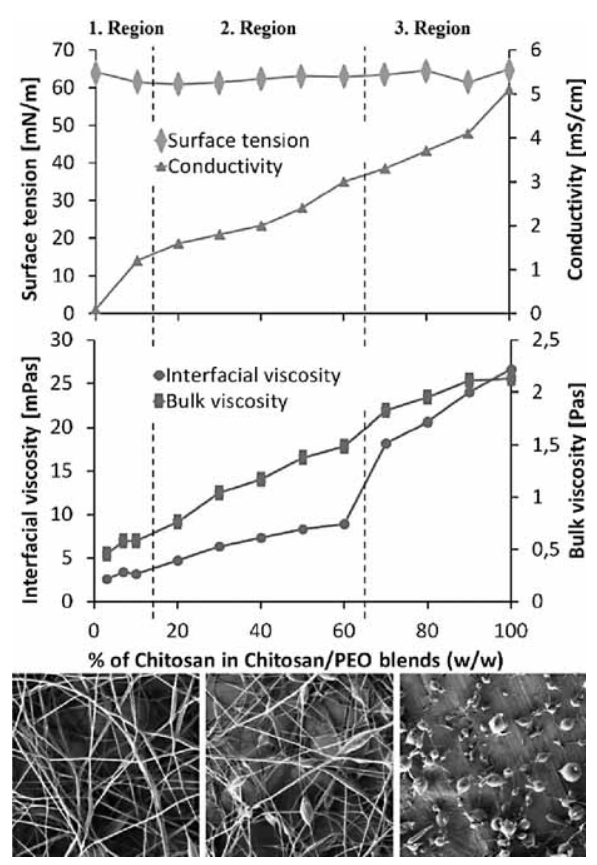




\section{CONCLUSIONS}

Development of various dilatational and shear interfacial measurement techniques enables an insight into the interfacial layers, their characteristics, their formation and their role in various systems. So far, studies exploring the influence of interfacial rheological characteristics have shown that the correlation is unique for each system and is far from straightforward. Furthermore, the interface must be analysed with both the dilatational and shear method, because these are two completely different but complementary methods. Dilatational deformation is primarily affected by the characteristics of the molecular structure at the interface, while shear deformation is primarily affected by the strength of the interfacial film, which is related to intermolecular interactions. While dilatational rheology plays an important role in short-term stability, interfacial shear viscosity is more closely related to long-term stability. Only by combining the results of both methods it is possible to gain complex information to help understand the correlation between the interfacial mechanical properties and the structures formed at the interfaces. Unfortunately, comprehensive studies evaluating both measuring principles are still lacking. Moreover, even much less is known about the role of interfacial rheological characteristics in electrospinning. We believe that due to the large increase in the interface during electrospinning, the correlation between the rheological characteristics of the interface and the nanofiber morphology is far more distinct than the correlation between the rheological characteristics in bulk and the nanofiber morphology. Therefore these relationships must be further explored to optimise the process of electrospinning.

Acknowledgements. - This work was financially supported by the Ministry of Education, Science, Culture and Sport of the Republic of Slovenia: P1 - 0189, J1 - 4236, $1000-09-310085$ and $1000-11-310213$.

\section{REFERENCES}

1. J. M. Rodríguez Patino, C. Carrera Sánchez and M. R. Rodríguez Niño, Implications of interfacial characteristics of food foaming agents, Adv. Colloid Interfac. 140 (2008) 95-113; DOI: 10.1016/ j.cis.2007.12.007.

2. R. Rošic, J. Pelipenko, M. Bešter-Rogač, S. Baumgartner and J. Kristl, Rheology of polymer solutions in predicting nanofiber formation by electrospinning, Eur. Polym. J. (2012); DOI: 10.1016/ j.eurpolymj.2012.05.001.

3. R. Miller, J. K. Ferri, A. Javadi, J. Krgel, N. Mucic and R. Wüstneck, Rheology of interfacial layers, Colloid Polym. Sci. 288 (2010) 937-950; DOI: 10.1007/s00396-010-2227-5.

4. J. Kocevar Nared, J. Kristl and J. Smid Korbar, Comparative rheological investigation of crude gastric mucin and natural gastric mucus, Biomaterials 18 (1997) 677-681; DOI: 10.1016/S0142-9612(96)00180-9.

5. M. Gasperlin, J. Kristl and J. Smid Korbar, Viscoelastic behaviour of semi-solid w/o emulsion systems, STP Pharma Sci. 7 (1997) 158-163.

6. M. Gasperlin, L. Tusar and M. Tusar, Viscosity prediction of lipophilic semisolid emulsion systems by neural network modeling, Int. J. Pharm. 196 (2000) 37-50; DOI: 10.1016/S0378-5173(99) 00443-3. 
J. Pelipenko et al.: Interfacial rheology: An overview of measuring techniques and its role in dispersions and electrospinning, Acta Pharm. 62 (2012) 123-140.

7. Z. Khattari, Y. Ruschel, H. Z. Wen, A. Fischer and T. M. Fischer, Compactification of a myelin mimetic Langmuir monolayer upon adsorption and unfolding of myelin basic protein, J. Phys. Chem. 109 (2005) 3402-3407; DOI: 10.1021/jp045493z.

8. B. S. Murray, Rheological properties of protein films, Curr. Opin. Colloid In. 16 (2011) 27-35; DOI: 10.1016/j.cocis.2010.06.005.

9. R. M. Prokop and A. W. Neumann, Measurement of the interfacial properties of lung surfactant, Curr. Opin. Colloid In. 1 (1996) 677-681; DOI: 10.1016/S1359-0294(96)80108-7.

10. R. Wüstneck, J. Perez-Gil, N. Wüstneck, A. Cruz, V. B. Fainerman and U. Pison, Interfacial properties of pulmonary surfactant layers, Adv. Colloid Interfac. 117 (2005) 33-58; DOI: 10.1016/j.cis. 2005.05.001.

11. J. Krägel and S. R. Derkatch, Interfacial shear rheology, Curr. Opin. Colloid In. 15 (2010) 246-255; DOI: $10.1016 /$ j.cocis.2010.02.001.

12. T. G. Mezger, The Rheology Handbook, $2^{\text {nd }}$ Edition, Vincentz Network, Hannover 2006, pp. $16-26$.

13. K. Masschaele, S. Vandebril, J. Vermant and B. Madivala, Rheology-Vol.1, EOLSS 2009, pp. 414-439.

14. T. F. Tadros, Applied Surfactants; Principles and Applications, Willey-VCH, Weinheim 2005, pp. $162-168$.

15. R. Miller and L. Liggieri, Interfacial Rheology, Vol. 1, Brill, Boston 2009, pp. 1-178.

16. A. Zupančič Valant, Uvod v reologijo, Univerza v Ljubljani, Fakulteta za kemijo in kemijsko tehnologijo, Ljubljana 2007, pp. 29-48.

17. R. J. Crawford, Plastics Engineering, $3^{\text {rd }}$ edition, Elsevier grad, United Kingdom 1998, pp. 84-95.

18. A. Torcello-Gómez, J. Maldonado-Valderrama, M. J. Gálvez-Ruiz, A. Martín-Rodríguez, M. A. Cabrerizo-Vílchez and J. Vicente, Surface rheology of sorbitan tristearate and $\beta$-lactoglobulin: Shear and dilatational behavior, J. Non-Newton. Fluid 166 (2011) 713-722; DOI: 10.1016/j.jnnfm. 2011.03.008.

19. J. Maldonado-Valderrama and J. M. Rodríguez Patino, Interfacial rheology of protein-surfactant mixtures, Curr. Opin. Colloid In. 15 (2010) 271-282; DOI: 10.1016/j.cocis.2009.12.004.

20. J. Krgel, S. R. Derkatch and R. Miller, Interfacial shear rheology of protein-surfactant layers, $A d v$. Colloid Interfac. 144 (2008) 38-53; DOI: 10.1016/j.cis.2008.08.010.

21. S. Reynaert, C. F. Brooks, P. Moldenaers, J. Vermant and G. G. Fuller, Analysis of the magnetic rod interfacial stress rheometer, J. Rheol. 52 (2008) 261-285; DOI: 10.1122/1.2798238.

22. T. Verwijlen, P. Moldenaers, H. A. Stone and J. Vermant, Study of the flow field in the magnetic rod interfacial stress rheometer, Langmuir 27 (2011) 9345-9358; DOI: 10.1021/la201109u.

23. J. Ding, H. E. Warriner and J. A. Zasadzinski, Magnetic needle viscometer for Langmuir monolayers, Langmuir 18 (2002) 2800-2806; DOI: 10.1021/la015589.

24. F. Ravera, G. Loglio and V. I. Kovalchuk, Interfacial dilational rheology by oscillating bubble/ drop methods, Curr. Opin. Colloid In. 15 (2010) 217-228; DOI: 10.1016/j.cocis.2010.04.001.

25. V. B. Fainerman, D. Möbius and R. Miller, Surfactants: Chemistry, Interfacial Properties, Applications, Elsevier Science, Amsterdam 2001, pp. 341-348.

26. B. A. Noskov, A. V. Akentiev, A. Yu. Bilibin, I. M. Zorin and R. Miller, Dilatational surface viscoelasticity of polymer solutions, Adv. Colloid Interfac. 104 (2003) 245-271; DOI: 10.1016/S0001-8686(03)00045-9.

27. B. A. Noskov, Dilational surface rheology of polymer and polymer/surfactant solutions, Curr. Opin. Colloid In. 15 (2010) 229-236; DOI: 10.1016/j.cocis.2010.01.006.

28. S. C. Russev, N. Alexandrov, K. G. Marinova, K. D. Danov, N. D. Denkov, L. Lyutov, V. Vulchev and C. Bilke-Krause, Instrument and methods for surface dilatational rheology measurements, Rev. Sci. Instrum. 79 (2008) 104102; DOI: 10.1063/1.3000569.

29. P. Gupta, C. Elkins, T. Long and G. Wilkes, Electrospinning of linear homopolymers of poly(methyl methacrylate): exploring relationships between fiber formation, viscosity, molecular weight 
J. Pelipenko et al.: Interfacial rheology: An overview of measuring techniques and its role in dispersions and electrospinning, Acta Pharm. 62 (2012) 123-140.

and concentration in a good solvent, Polymer 46 (2005) 4799-4810; DOI: 10.1016/j.polymer.2005. 04.021.

30. F. Ravera, G. Loglio, P. Pandolfini, E. Santini and L. Liggieri, Determination of the dilational viscoelasticity by the oscillating drop/bubble method in a capillary pressure tensiometer, Colloid. Surface. A 365 (2010) 2-13; DOI: 10.1016/j.colsurfa.2010.01.040.

31. P. Wilde, A. Mackie, F. Husband, P. Gunning and V. Morris, Proteins and emulsifiers at liquid interfaces, Adv. Colloid Interfac. 108-109 (2004) 63-71; DOI: 10.1016/j.cis.2003.10.011.

32. V. B. Fainerman, E. H. Lucassen-Reynders and R. Miller, Description of the adsorption behaviour of proteins at water/fluid interfaces in the framework of a two-dimensional solution model, Adv. Colloid Interfac. 106 (2003) 237-259; DOI: 10.1016/S0001-8686(03)00112-X.

33. D. Langevin, Influence of interfacial rheology on foam and emulsion properties, Adv. Colloid Interfac. 88 (2000) 209-222; DOI: 10.1016/S0001-8686(00)00045-2.

34. J. L. Ventureira, A. J. Bolontrade, F. Speroni, E. David-Briand, A. A. Scilingo, M. H. Ropers, F. Boury, M. C. Añón and M. Anton, Interfacial and emulsifying properties of amaranth (Amaranthus hypochondriacus) protein isolates under different conditions of $\mathrm{pH}$, LWT-Food Sci. Technol. 45 (2012) 1-7; DOI: 10.1016/j.lwt.2011.07.024.

35. M. A. Bos and T. Vliet, Interfacial rheological properties of adsorbed protein layers and surfactants: a review, Adv. Colloid Interfac. 91 (2001) 437-471; DOI: 10.1016/S0001-8686(00)00077-4.

36. A. G. Bykov, Shi-Yow Lin, G. Loglio, V. V. Lyadinskaya, R. Miller and B. A. Noskov, Impact of surfactant chain length on dynamic surface properties of alkyltrimethylammonium bromide/ polyacrylic acid solutions, Colloid. Surface. A 354 (2010) 382-389; DOI: 10.1016/j.colsurfa.2009. 09.015.

37. W. J. Mcauley, D. S. Jones and V. L. Kett, Characterisation of the interaction of lactate dehydrogenase with Tween-20 using isothermal titration calorimetry, interfacial rheometry and surface tension measurements, J. Pharm. Sci. 98 (2009) 2659-2669; DOI: 10.1002/jps.21640.

38. E. Dickinson, Adsorbed protein layers at fluid interfaces: interactions, structure and surface rheology, Colloid. Surface. B 15 (1999) 161-176; DOI: 10.1016/S0927-7765(99)00042-9.

39. A. R. Mackie, A. P. Gunning, P. J. Wilde and V. J. Morris, Orogenic displacement of protein from the oil/water interface, Langmuir 16 (2000) 2242-2247; DOI: 10.1021/la990711e.

40. C. Carrera Sánchez, M. Rosario Rodríguez Niño, A. Lucero Caro and J. M. Rodríguez Patino, Biopolymers and emulsifiers at the air-water interface, Implications in food colloid formulations, J. Food Eng. 67 (2005) 225-234; DOI: 10.1016/j.jfoodeng.2004.05.065.

41. A. G. Bykov, Shi-Yow Lin, G. Loglio, R. Miller and B. A. Noskov, Kinetics of adsorption layer formation in solutions of polyacid/surfactant complexes, J. Phys. Chem. C 113 (2009) 5664-5671; DOI: $10.1021 /$ jp $810471 y$.

42. B. A. Noskov, G. Loglio and R. Miller, Dilational surface visco-elasticity of polyelectrolyte/surfactant solutions: Formation of heterogeneous adsorption layers, Adv. Colloid Interfac. 168 (2011) 179-197; DOI: 10.1016/j.cis.2011.02.010.

43. J. M. Rodríguez Patino, C. C. Sánchez, M. C. Fernández and M. R. Niño, Protein displacement by monoglyceride at the air-water interface evaluated by surface shear rheology combined with Brewster angle microscopy, J. Phys. Chem. B 111 (2007) 8305-8313; DOI: 10.1021/jp071994j.

44. S. Vandebril, J. Vermant and P. Moldenaers, Efficiently suppressing coalescence in polymer blends using nanoparticles: role of interfacial rheology, Soft Matter 6 (2010) 3353-3362; DOI: 10.1039/ b927299b.

45. B. Madivala, S. Vandebril, J. Fransaerb and J. Vermant, Exploiting particle shape in solid stabilized emulsions, Soft Matter 5 (2009) 1717-1727; DOI: 10.1039/b816680c.

46. P. A. Wierenga and H. Gruppen, New views on foams from protein solutions, Curr. Opin. Colloid In. 15 (2010) 365-373; DOI: 10.1016/j.cocis.2010.05.017. 
J. Pelipenko et al.: Interfacial rheology: An overview of measuring techniques and its role in dispersions and electrospinning, Acta Pharm. 62 (2012) 123-140.

47. L. Piazza, J. Gigli and A. Bulbafello, Interfacial rheology study of espresso coffee foam structure and properties, J. Food Eng. 84 (2008) 420-429; DOI: 10.1016/j.jfoodeng.2007.06.001.

48. T. Croguennec, A. Renault, S. Beaufils, J. Dubois and S. Pezennec, Interfacial properties of heat-treated ovalbumin, J. Colloid Interf. Sci. 315 (2007) 627-636; DOI: 10.1016/j.jcis.2007.07.041.

49. J. Maldonado-Valderrama, A. Martßn-Rodriguez, M. J. Gálvez-Ruiz, R. Miller, D. Langevin and M. A. Cabrerizo-Vílchez, Foams and emulsions of $\beta$-casein examined by interfacial rheology, Colloid. Surface. A 323 (2008) 116-122; DOI: 10.1016/j.colsurfa.2007.11.003.

50. T. J. Wooster and M. A. Augustin, Rheology of whey protein-dextran conjugate films at the air/ water interface, Food Hydrocolloid. 21 (2007) 1072-1080; DOI: 10.1016/j.foodhyd.2006.07.015.

51. D. A. Kim, M. Cornec and G. Narsimhan, Effect of thermal treatment on interfacial properties of $\beta$-lactoglobulin, J. Colloid Interf. Sci. 285 (2005) 100-109; DOI: 10.1016/j.jcis.2004.10.044.

52. A. Sanfeld and A. Steinchen, Emulsions stability, from dilute to dense emulsions - Role of drops deformation, Adv. Colloid Interfac. 140 (2008) 1-65; DOI: 10.1016/j.cis.2007.12.005.

53. M. Cegnar, J. Kristl and J. Kos, Nanoscale polymer carriers to deliver chemotherapeutic agents to tumours, Expert Opin. Biol. Th. 5 (2005) 1557-1569; DOI: 10.1517/14712598.5.12.1557.

54. K. Teskac and J. Kristl, The evidence for solid lipid nanoparticles mediated cell uptake of resveratrol, Int. J. Pharm. 390 (2010) 61-69; DOI: 10.1016/j.ijpharm.2009.10.011.

55. N. Bhardwaj and S. C. Kundu, Electrospinning: A fascinating fiber fabrication technique, Biotechnol. Adv. 28 (2010) 325-347; DOI: 10.1016/j.biotechadv.2010.01.004.

56. G. C. Rutledge and S. V. Fridrikh, Formation of fibers by electrospinning, Adv. Drug Deliver. Rev. 59 (2007) 1384-1391; DOI: 10.1016/j.addr.2007.04.020.

57. R. Rošic, P. Kocbek, S. Baumgartner and J. Kristl, Electro-spun hydroxyethyl cellulose nanofibers: The relationship between structure and process, J. Drug Deliv. Sci. Tec. 21 (2011) 229-236.

58. X. Geng, O. H. Kwon and J. Jang, Electrospinning of chitosan dissolved in concentrated acetic acid solution, Biomaterials 26 (2005) 5427-5432; DOI: 10.1016/j.biomaterials.2005.01.066.

59. M. G. McKee, G. L. Wilkes, R. H. Colby and T. E. Long, Correlations of solution rheology with electrospun fiber formation of linear and branched polyesters, Macromolecules 37 (2004) 1760-1767; DOI: $10.1021 / \mathrm{ma} 035689 \mathrm{~h}$.

60. Q. P. Pham, U. Sharma and A. G. Mikos, Electrospinning of polymeric nanofibers for tissue engineering applications: A review, Tissue Eng. 12 (2006) 1197-1211; DOI: 10.1089/ten.2006.12.1197.

61. O. Regev, S. Vandebril and E. C. Zussman, The role of interfacial viscoelasticity in the stabilization of an electrospun jet, Polymer 51 (2010) 2611-2620; DOI: 10.1016/j.polymer.2010.03.061.

62. P. Erni, P. Fischer, E. J. Windhab, V. Kusnezov, H. Stettin and J. Läuger, Stress- and strain-controlled measurements of interfacial shear viscosity and viscoelasticity at liquid/liquid and gas / liquid interfaces, Rev. Sci. Instrum. 74 (2003) 4916-4925; DOI: 10.1063/1.1614433.

63. P. Ahlin, J. Kristl, M. Sentjurc, J. Strancar and S. Pecar, Influence of spin probe structure on its distribution in SLN dispersions, Int. J. Pharm. 196 (2000) 241-244; DOI: 10.1016/S0378-5173(99) 00431-7.

64. P. Ahlin, J. Kristl, S. Pecar, J. Strancar and M. Sentjurc, The effect of lipophilicity of spin-labeled compounds on their distribution in solid lipid nanoparticle dispersions studied by electron paramagnetic resonance, J. Pharm. Sci. 92 (2001) 58-66; DOI: 10.1002/jps.10277. 
J. Pelipenko et al.: Interfacial rheology: An overview of measuring techniques and its role in dispersions and electrospinning, Acta Pharm. 62 (2012) 123-140.

POVZETEK

\section{Medfazna reologija: Pregled merilnih tehnik in njen pomen $\mathrm{v}$ disperzijah in elekrostatskemu sukanju}

JAN PELIPENKO, JULIJANA KRISTL, ROMANA ROŠIC, SAŠA BAUMGARTNER in PETRA KOCBEK

Medfazne reološke lastnosti so še dokaj neraziskane. Šele pred kratkim so razvili metode, s katerimi je mogoče z zadostno občutljivostjo in natančnostjo določiti viskoelastične lastnosti medfaze. Medfazna reologija opisuje odnos med deformacijo medfaze in silo, ki to deformacijo povzroči. Zaradi različnih deformacij medfazne plasti (strig in raztezanje, oziroma krčenje) se tudi medfazna reologija deli na strižno in dilatacijsko. Strižne reološke lastnosti medfaze se odražajo v dolgotrajni stabilnosti disperzij, medtem ko se dilatacijske predvsem v kratkotrajni stabilnosti. Poznavanje medfaznih reoloških lastnosti je pomembno $\mathrm{v}$ sistemih $\mathrm{z}$ velikimi medfaznimi površinami, kot so emulzije in pene ter pri procesih, kjer pride do velikega povečanja medfazne površine, kot je elektrostatsko sukanje nanovlaken.

Ključne besede: medfazna reologija, emulzije, pene, elektrostatsko sukanje, nanovlakna, nanotehnologija

Univerza v Ljubljani, Fakulteta za Farmacijo, Ljubljana, Slovenija 